\title{
Colombia en la guerra de Corea
}

\section{Colombia in Korea's war}

\author{
Adolfo León Atehortúa Cruz*
}

\section{Resumen}

Este artículo se ocupa de cinco aspectos poco explorados con respecto a la Guerra de Corea: la decisión de participar en el conflicto por parte del gobierno colombiano; la selección de los oficiales al frente del Batallón Colombia; la búsqueda de armas para el gobierno de Laureano Gómez; la experiencia obtenida por el Ejército de Colombia, y la influencia norteamericana profundizada con ella.

\section{Palabras clave:}

Ejército Nacional, historia del Ejército, Guerra de Corea, Laureano Gómez, Colombia en Corea, Estados Unidos-Colombia.

\section{Abstract}

This article refers five aspects scarcely explored on the Korea's War: the Colombian decision of participating in the conflict; the selection of the officials in the Battalion Colombia; the search for weapons by Laureano Gómez; the experience obtained by the Colombian Army, and the North American influence established on that period.

Key words:

National army, History of the Army, Korea's War, Laureano Gómez, Colombia as participant, USA and Colombia.

Profesor del Departamento de Ciencias Sociales de la Universidad Pedagógica Nacional. adolfoatehortua@cable.net.co. 


\section{Presentación}

La participación de Colombia en la Guerra de Corea se ha examinado desde ámbitos diversos y por variados autores. Este artículo no pretende ocuparse de aspectos en detalle que constituyen materia extensa y cuidadosa. Su propósito se dirige a cinco apartados solamente: la decisión de participar en el conflicto por parte del gobierno colombiano; la manera en que realizó la selección de los oficiales que habrían de ponerse al frente del Batallón Colombia; la participación en Corea como mecanismo para obtener armas; el significado de Corea como experiencia para el Ejército de Colombia, y el giro hacia la influencia norteamericana.

\section{Colombia va a la guerra}

La discusión sobre la participación de Colombia en Corea se realizó a partir de la solicitud elevada por las Naciones Unidas durante el gobierno de Mariano Ospina Pérez (1946-1950). Estados Unidos buscaba la más amplia participación latinoamericana, en tanto ello mostraría el interés de Occidente y del "mundo libre" para enfrentar al comunismo. De esta forma sus bajas serían reducidas y la guerra lograría un verdadero alcance internacional con menor costo para Estados Unidos. Se esperaba una fuerza colectiva a través de la OEA, o fuerzas especiales de carácter nacional. Sin embargo, las condiciones de cada país frustraron el propósito estadounidense. Latinoamérica no aceptaba el pago inmediato por el suministro de armas y equipos, y Estados Unidos exigía el aporte de divisiones con más de diez mil hombres. Solo después se aceptó que el mínimo de la ayuda sería mil unidades, pero continuó exigiéndose el desembolso inmediato para la compra de equipos militares.

En un principio, Ospina Pérez ofreció apoyo a Truman "en la forma en que el desarrollo de los acontecimientos lo indicare necesaria" "para el cumplimiento de las resoluciones del Consejo de Seguridad de la ONU", y reafirmó su entero respaldo a la política internacional de Estados Unidos'. Sin embargo, cuando la cancillería recibió oficial-

1 El Siglo, 29 de agosto de 1950. mente la petición de participación, el ministro de Guerra, Evaristo Sourdís, respondió que Colombia solo contaba con fuerzas para atender sus propias necesidades. Colombia estaba dispuesta a cumplir sus compromisos pero era difícil hacerlo a costa del sacrificio de su propia tranquilidad2.

No fue una negativa contundente. Colombia se preocupaba por la obligación de pagar todo el apoyo logístico y "regateaba" su precio. Su posición, en ese momento, era muy similar a la asumida por las demás naciones latinoamericanas. Estados Unidos ofreció una fórmula de arreglo: lo importante era decidir la participación. La forma de pago podría arreglarse a posteriori.

No obstante, la decisión definitiva quedó en manos del sucesor de Ospina Pérez. Laureano Gómez se posesionó como presidente de Colombia el 7 de agosto de 1950 y empezó, con su discurso, a "mostrar la posición favorable" que Estados Unidos le exigía. Halagó a las Fuerzas Armadas por su lealtad y decisión contra las amenazas de la "tiranía comunista" y prometió dotarlas de "medios técnicos adecuados". Alabó a Estados Unidos como "defensor de la soberanía e independencia de los pueblos", “de la libertad y de la dignidad que el comunismo quiere destruir", y resaltó su lucha en Corea con un párrafo plagado de ditirambos:

Los Estados Unidos están enviando la vanguardia de su juventud a una lucha sangrienta en defensa de esos principios, y mi espíritu no quedaría satisfecho si en estos momentos mis labios dejaran de pronunciar las palabras de admiración y reconocimiento por el heroico esfuerzo que se hace para salvar la civilización ${ }^{3}$.

Gómez abrió la puerta para que Colombia participara en la cruzada y antes de un mes su ministro de Guerra viajó a Washington para concretar la

2 El Tiempo, 15 y 28 de julio de 1950. Según este diario, cerca de 500 colombianos se ofrecieron como voluntarios a la embajada de Estados Unidos, pero esta lamentó la posibilidad de utilizar sus servicios. Ante la negativa inicial de Colombia, un militar "vendió su casa" y se dispuso a viajar con su familia a estados Unidos para enrolarse como voluntario. El Tiempo, 18 de julio y 25 de agosto de 1950.

3 Citado por Álvaro Tirado Mejía. (1989). El gobierno de Laureano Gómez, de la dictadura civil a la dictadura militar. En Nueva Historia de Colombia. Bogotá: Planeta, Volumen II, Capítulo IV, p. 90. 
decisión. El Decreto 3230 del 23 de octubre de 1950 dispuso el envío de la fragata Almirante Padilla, destinada a patrullar aguas de Corea como parte de la VI Flota Estadounidense, y pocos días después el embajador Zuleta Ángel ofreció los servicios de un batallón de infantería.

\section{La selección de oficiales}

La decisión de Laureano Gómez salvó el honor de Estados Unidos, en tanto Colombia se convirtió en el único país latinoamericano que ofreció su concurso para combatir en Corea. Frente a ello, la oposición liberal no negó la importancia de "apoyar al país del norte en su lucha por la paz y la seguridad del mundo", pero advirtió su desconfianza con respecto a la entrega de armamento que pudiera utilizarse con fines autoritarios. Incluso, según El Tiempo, lo mejor sería "enviar a diez mil fieras chulavitas para luchar contra las fieras comunistas" y, al mismo tiempo, "pacificar al país"4.

La respuesta de El Siglo dejó entrever otro de los objetivos de Laureano Gómez al disponer la participación de Colombia en Corea. Es claro que el primero de ellos reivindicaba las posiciones y la conducta de Gómez ante Estados Unidos; exorcizaba sus viejos demonios de oposición al Tratado Urrutia-Thomson y de apoyo a la Alemania nazi, y se congraciaba con la potencia del norte. El segundo, sin duda, buscaba la ayuda militar para enfrentar al enemigo interno. Según el periódico del nuevo Presidente, el suministro de armas, por parte de Estados Unidos, era una necesidad imperiosa en la lucha contra el comunismo. De lo contrario, la debilidad de Colombia podría convertirla en fácil presa de los comunistas 5 .

El problema, sin embargo, era más complejo: el gobierno se enredaba al definir a su enemigo interno y el Ejército no sabía identificarlo. En un burdo intento por trasladar a Colombia las estrategias recientes de la Guerra Fría, el gobierno buscaba asimilar la oposición, el liberalismo y las guerrillas liberales, al comunismo. Estados Unidos no lo

\footnotetext{
4 El Tiempo, 22 de agosto y 28 de septiembre de 1950.

5 El Siglo, 24 de agosto de 1950.
}

creía; conocía muy bien a Santos, a López, a Lleras, y conocía muy bien a Laureano Gómez y al propio Partido Comunista criollo.

Esta no era, tampoco, una situación exclusivamente colombiana. En América Latina, varios gobiernos endilgaban a la oposición los epítetos del comunismo para atraer el apoyo estadounidense y reprimirla con saña. Por esa razón, Estados Unidos prefería predicar el panamericanismo para el caso de una agresión extracontinental o estrictamente dirigido contra la Unión Soviética. El gobierno insistía en que el comunismo internacional penetraba disfrazado de liberalismo para destruir la democracia. Era la idea desarrollada del famoso "basilisco": un "monstruo liberal" con "brazos masónicos" y una "diminuta cabeza comunista".

Frente a semejante discurso, las Fuerzas Militares no hallaban fácilmente a su enemigo. No pocos oficiales comprendían en silencio que la visión del gobierno era, ante todo, una visión de partido. Entrenados para las guerras convencionales y deseosos de continuar una carrera profesional con dignidad, prefirieron buscar al enemigo más allá de la frontera.

No es posible definir cuántos oficiales encontraron en la Guerra de Corea la oportunidad para escapar a la situación comprometedora en la que el Ejército venía moviéndose frente a la dinámica de la violencia: prefirieron combatir en Corea antes que matar compatriotas en los Llanos. Varias décadas más tarde, algunos confesaron que "no entendían por qué motivo habían acudido a un teatro extraño a su geografía, ideales, valores y aspiraciones" ${ }^{\text {". Otros, }}$ en cambio, lo dijeron sin tapujos:

No tengo mayor conocimiento de lo que es y no es el comunismo; además poco me interesa. Sé que niega a Dios y para mí es suficiente como cristiano, militar en las filas contrarias... Me siento algo así como un cruzado potencial... pero también tengo mis reservas sobre lo que llamamos "democracia", especialmente con lo que ha ocurrido en el país en estos tres últimos años.

6 Véase Torres, Pablo. (1958). Colombia en la Guerra de Corea. Bogotá: Impresiones de un Combatiente, spi. 
Adoro mi carrera y sé que me dolería mucho dejarla. Pero me siento hastiado y sin motivo para combatir en una contienda que habrá de cobrar vidas y sangre de hermanos... Este viaje a Corea me abre la oportunidad de realizarme como soldado y llegar a vivir la emoción de la guerra y la ilusión de la gloria militar que no se podrá encontrar nunca en una lucha intestina... Es la oportunidad de realizar mi carrera militar y de sustraerme a una lucha fratricida que me ha dejado tremendas decepciones en mi reciente experiencia en los Llanos Orientales.

No deja de ser irónico, ir a luchar por una democracia tan lejos de nuestras fronteras, cuando aquí vemos cómo se van desvaneciendo esos ideales...7.

En estas circunstancias, cuando el gobierno de Gómez ofreció para Corea un batallón de infantería, muchos oficiales hastiados del conflicto interno se inscribieron como voluntarios. No obstante, existieron también otras motivaciones para ese enganche más o menos forzado: desde el desempleo de muchos reservistas y prófugos de la cárcel -pasando por aquellos que buscaban movilidad social y militar-, hasta llegar a los aventureros y románticos que fueron prácticamente "enlazados" momentos antes de que el Batallón Colombia zarpara con destino a la guerra:

Por lo menos quince hombres se sumaron en su condición de "espontáneos" de último momento, durante la marcha al puerto, algunos de ellos civiles que ni siquiera tienen instrucción militar ni han sido legalmente incorporados al Ejército8.

Otros oficiales fueron vinculados por sus superiores para aislarlos de la situación interna o en razón de sus presuntas filiaciones partidistas. Según lo reconoció un sargento al entonces teniente Gabriel Puyana, "los hemos seleccionado por su pueblo de origen":

Se escogió a todos aquellos que creemos que son liberales o por lo menos que sus familiares son

\footnotetext{
7 Puyana García, Gabriel. ¡Por la libertad en tierra extraña! Op. cit., pp. 47,48 y 65 .

8 Ibídem, p. 80.
}

de este partido y estamos seguros de no habernos equivocado 9 .

Según el mayor Gonzalo Bermúdez, los combatientes fueron alistados impositivamente aunque se les haya querido presentar como "voluntarios"10. En realidad, todo aquel que se negaba era retirado de la fuerza de inmediato. Las circunstancias se aprovecharon para acelerar la conservatización del Ejército, enviando a Corea un número proporcionalmente mayor de oficiales y suboficiales liberales' ${ }^{11}$. Aunque El Siglo negó que hubiese primado un criterio partidista en la escogencia del Batallón Colombia12, Álvaro Valencia Tovar confiesa que fue sorprendido con la misión, al igual que muchos otros, quienes atribuían su designación a "razones partidistas o a animadversiones de superiores". Fueron "voluntarios del dedo índice" con una frase penetrante a flor de labios: “¿Por qué luchar por la libertad y la democracia en otro país, cuando en el nuestro ambas estaban desapareciendo?"13.

La moral de los primeros seleccionados no fue muy propicia. Una investigación de inteligencia determinó que muchos efectivos "no querían seguir sirviendo a un ejército que utilizaba patrones políticos para medir la calidad de sus hombres" y que, en su criterio, a Corea se iba "no a servir a la patria sino a un gobierno que consideraba enemigos a los coreanos". Tras la defección de algunos oficiales, el coronel Polanía reunió a toda su tropa y pidió un paso al frente a quienes no fueran voluntarios. El resultado en los soldados, según Valencia Tovar, "fue catastrófico". Se tuvo que acudir entonces a los reservistas y a explorar hasta el fondo los inscritos como voluntarios. "Un par de prófugos y algunos reconocidos hampones” ingresaron por esa vía al Batallón Colombia ${ }^{14}$.

9 Ibídem, p. 64.

10 Bermúdez, Gonzalo. Op. cit., p. 63.

11 Esta información la obtuvo Francisco Leal en entrevistas realizadas a militares y ex militares entre 1966 y 1969. Op. cit., p. 81.

12 El Siglo, enero 16 de 1951.

13 Valencia Tovar, Álvaro. Testimonio..., pp. 149-150.

14 Valencia Tovar, Álvaro y Sandoval Franky, Jairo. (2001). Colombia en la guerra de Corea. La historia secreta. Bogotá: Planeta, pp. 230 y 231. Con la versión coincide Gabriel Puyana García. op. cit. 
En una nota confidencial, el Secretario de Estado de Estados Unidos admitió:

Como sucede en toda unidad militar colombiana, hubo algunas deserciones debidas principalmente a las condiciones de hacinamiento padecidas por el Batallón en Bogotá, y a que algunos comandantes de varias unidades del país, en lugar de presentar a quienes se ofrecieron como voluntarios para Corea, presentaron a elementos que deseaban sacar de sus unidades... La unidad llegó a Buenaventura con más hombres que cuando partió de Bogotá, debido a que varios desertores regresaron a filas y dos civiles se reclutaron en Cali cuando el tren pasó por esa ciudad ${ }^{15}$.

\section{Laureano en busca de armas}

El gobierno, a decir verdad, no obtuvo la cantidad ni la calidad del armamento que esperaba. De entrada, en la nota que ofreció la participación militar de Colombia, el embajador ante Estados Unidos advirtió al Secretario de Estado, Dean Acheson, que el Batallón se encontraba equipado "con variedad irregular de armamento estadounidense y europeo" y que, por tanto, era absolutamente necesario "dotarlo de las armas de infantería norteamericanas y entrenarlo para su uso"16. Lo extraño pero muy significativo de la nota es que esta se hacía por parte del embajador ante Estados Unidos y no del ministro de Relaciones Exteriores, y que se dirigía al Departamento de Estado de ese país y no a las Naciones Unidas, como organización que solicitaba el concurso militar de sus países miembros.

En el trámite interno de la solicitud, los funcionarios estadounidenses consideraron que la oferta colombiana no reunía los criterios de asistencia establecidos, que no ofrecía apoyo de combate o de servicio diferente del médico, que al batallón había

15 M. Acheson a misiones, embajadas y consulados de Estados Unidos en Latinoamérica. Foreign Relations of the United Status, vol II, 1951 Washington: U.S. Printing Office, 1979, p. 1305-1306. Las condiciones de hacinamiento y la incorporación de civiles a última hora son coincidentes con los testimonios de Puyana García y Valencia Tovar en sus obras citadas.

16 Nota diplomática de Eduardo Zuleta Ángel al Secretario de Estado, noviembre 14 de 1950. Archivo Nacional de Estados Unidos. 816.047 . que equiparlo, dotarlo de provisiones y además transportarlo y que, aunque la disciplina del ejército era buena, su moral era "mediana" y su capacidad de combate, "pobre". A pesar de todo ello, concluyeron, debe aceptarse "desde el punto de vista político"17.

En 1951, un año después del traslado del Batallón Colombia a Corea, el ministro de Guerra, Roberto Urdaneta, discutió en Estados Unidos la posibilidad de obtener abastecimientos y armas para las Fuerzas Militares 18 . La respuesta fue negativa pero diplomática: la ayuda solo podría entregarse en el marco de un acuerdo bilateral de asistencia militar que no existía. Estados Unidos nombró, entonces, una comisión que se encargaría de estudiar las necesidades de las Fuerzas Militares de Colombia, la cual fue compuesta por el general Edwin Silbert, el capitán A. P. Talbert de la Marina, el coronel William Cleveland de la aviación, el capitán Harry Pete del Ejército y el embajador en Colombia, Capus Waynick. La comisión viajó a Bogotá en enero de 1952 y se reunió con su similar colombiana compuesta por el entonces ministro de Guerra, José María Bernal, el canciller Gonzalo Restrepo, el comandante superior de las Fuerzas Militares y los comandantes de las tres armas.

Para el liberalismo, sin embargo, la venta de armas al gobierno de Laureano Gómez y Urdaneta constituía un grave riesgo y, por esa razón, intentó alegar razones de principio para rechazar la posibilidad del acuerdo:

Los pactos bilaterales debilitan inevitablemente la amplia concepción solidarista de los textos interamericanos y, a cambio de buscar una parcial cooperación militar, vulneran el valor moral y político de la misión completa de todos los países americanos $^{19}$

Fue inútil. El Pacto de Ayuda Militar se firmó en abril de 1952 y ambos países se comprometieron a "suministrar los equipos, materiales, servicios y demás ayuda militar" "para fomentar y mantener la paz del hemisferio occidental". No obstante, el Pacto

17 Ibidem. Notas al margen y consecutivas. G-3 files, NND 816.047.

18 El Espectador, 31 de mayo de 1951.

19 El Tiempo, 12 de febrero de 1952 
advirtió que Colombia se comprometía "a hacer uso eficaz de la ayuda que reciba del gobierno de los Estados Unidos" "para llevar a efecto los planes de defensa aceptados por ambos gobiernos", sin dedicarla "a otros fines que no sean aquellos para los cuales se suministró,'“a menos que previamente se obtenga la anuencia del gobierno de los Estados Unidos”. Los equipos y materiales que ya no sean necesarios para los fines para los cuales se facilitaron, estableció el pacto, "se devolverán al gobierno que suministró la ayuda"20. Para Estados Unidos, por consiguiente, era claro el propósito de que la ayuda militar ofrecida al gobierno de Laureano Gómez no fuera utilizada en el conflicto interno.

En ese mismo momento, Colombia y Estados Unidos discutían el pago de los recursos aportados por la potencia del norte para el Batallón Colombia en Corea. Según el Departamento de Estado, la situación era delicada. De un lado, presionar a Colombia para el pago podía desalentar la participación de otras naciones pero, de otro lado, aceptar su moratoria desestimulaba el pago que otros países efectuaban cumplidamente a Estados Unidos con el mismo propósito. La decisión apuntaba, entonces, a ejercer presión sobre Colombia y obtener, al menos, una parte del pago'21.

Colombia respondió que solo podría responsabilizarse del pago y asistencia al personal asignado en Corea pero que, definitivamente, estaba incapacitada para reembolsar a Estados Unidos todo lo aportado en materia militar y logística. De lo contrario, difícilmente podría continuar con sus fuerzas en Corea. Esta última afirmación asustó a los estadounidenses. El Subsecretario de Estado para asuntos latinoamericanos, Edgard Miller, informó al embajador que el asunto sería reconsiderado con benevolencia, teniendo en cuenta las dificultades de Colombia y su valiosa contribución militar22.

La situación fue aprovechada por el gobierno colombiano para reiterar sus solicitudes de arma-

20 El Espectador, 17 de abril de 1952.

21 Foreign Relations of the United Status, vol. IV, 1952-1954. Washington: U.S. Printing Office, 1979, pp. 1307-1308.

22 Ibídem, p. 772 y 773. mento. En primer lugar, desde luego, Colombia descartó cualquier posibilidad de retirarse de Corea y así lo notificó oficialmente a Miller. Poco después, el ministro de Guerra, José María Bernal, declaró al país en "ambiente de paz" y anunció su viaje a Estados Unidos "con el objeto de tratar cuestiones relacionadas con los suministros de equipo para el Ejército Nacional, modernizarlo y ponerlo en condiciones de atender el orden público y la defensa exterior"23. Previamente, el embajador anunció su visita y, para reforzar la solicitud de armamento, advirtió que en la opinión pública existía la imagen de que Estados Unidos "no trataba bien a Colombia" y "no le agradecía lo suficiente su participación en Corea" ${ }^{24}$. Al llegar a Washington, el ministro señaló que Colombia vivía "dentro de la más pura democracia", "en franca prosperidad" y "luchando contra el comunismo"25. Anunció la "plena identidad de intereses" con Estados Unidos y la posibilidad de adquirir "otra fragata para enviar a Corea", si se obtenía la venta de armamento. Entregó una lista de armas por un monto cercano a los tres millones de dólares que "debía entregarse a la mayor brevedad" y concretó un primer embarque en cumplimiento al Programa de Asistencia Militar, para finales de julio. Según su sentencia, si Colombia no definía su situación interna con las guerrillas comunistas, podría perder la posibilidad de ayudar en la defensa continental.

Para el Departamento de Estado la situación era ambigua. El Estado colombiano se negaba a cancelar los aportes que Estados Unidos brindaba a su batallón en Corea, alegando dificultades financieras, pero al mismo tiempo solicitaba armas y ofrecía otra fragata. Además, la capacidad de pago y las reservas en oro eran tangibles para Colombia, y no veía razón para reconsiderar los reembolsos exigidos. Sin embargo, la situación debía tratarse con delicadeza: a Colombia le importaba más el conflicto interno y la represión de sus crecientes gue-

23 El Tiempo, 11 de junio de 1952.

24 Foreign Relations of the United Status, vol IV, 1952-1954. op. cit., pp. 772-772.

25 Ibídem, 13 de junio de 1952. 
rrillas, que la lucha contra el comunismo en Corea. Por consiguiente, su amenaza de abandonar aquel país no debía desestimarse. Además, diplomáticos y militares estadounidenses habían aceptado en su momento que la deuda podía considerarse nominal y reducirse. La alternativa era ofrecer armamento regular pero no antipersonal.

Enterado de las negociaciones en Washington, el liberalismo acusó al Ejército de "aplicar la pena de muerte" y presentó ante el Senado fuertes cargos sobre su conducta en diversas regiones del país 26 . Germán Arciniegas, asilado en Washington, envió una carta al Times en la que acusó al Ejército por el cierre del Congreso y por haberse convertido en "instrumento de partido" que "sistemáticamente, con la asistencia de la policía, lleva a cabo una política de violencia conforme con la determinación del gobierno de mantenerse en el poder mediante el terror". Su carta sentenciaba:

Si Washington ahora proporciona armas a un gobierno que ha borrado el nombre de Colombia de la lista de las naciones democráticas de América, dejará una inextinguible amargura en todos aquellos colombianos -la mayoría- que han padecido los despiadados e insensatos desmanes de una bárbara dictadura ${ }^{27}$.

El Ministerio respondió a las acusaciones liberales con un homenaje a los caídos en Corea y en defensa del orden público ${ }^{28}$ y responsabilizó al "comunismo bandolero" por la situación del país. Días más tarde el Presidente viajó a los Llanos Orientales para rendir homenaje al Ejército y entregó la Cruz de Boyacá a once unidades del Ejército "por acción distinguida en tareas de orden público"29. En una campaña sin precedentes, los directorios conservadores de todo el país impulsaron la elaboración y envío de mensajes al Presidente, ofreciendo respaldo

26 El Siglo, 10 de julio de 1952.

27 Arciniegas, Germán. (1954). Entre la libertad y el miedo. Santiago de Chile: Editorial del Pacífico.

28 Ibídem, 12 de julio de 1952.

29 El Tiempo, 24 de julio de 1952. al primer mandatario y "rechazo a los ataques contra el Ejército"30.

La presión de Colombia continuó. Durante el mes de julio, El Siglo publicó diversas noticias sobre acciones heroicas de los soldados colombianos en Corea y se multiplicaron los panegíricos al Ejército y sus víctimas. En agosto se otorgó ascenso póstumo y Orden de Boyacá a todos los miembros del Ejército caídos en acción en los Llanos, y se ordenó un duelo nacional de tres días. Un lector desprevenido podría pensar que el Ejército colombiano libraba dos guerras: una en Corea y otra en los Llanos, con altas dosis de heroísmo y muerte.

El ministro de Guerra, José María Bernal, celebró el 29 de agosto una conferencia pública en la que definió de manera singular al enemigo:

El comunismo, enemigo universal, opera en todo el mundo con incesante actividad y con sistemas idénticos pero ajustándose en cada sitio a las peculiaridades propias del terreno y adoptando la denominación más adecuada para el logro de sus propósitos. Echa mano en cada país de la bandera de la oposición para sembrar el caos a todo trance. (En Colombia) al menos en las apariencias, el comunismo opera a sus anchas bajo la bandera del liberalismo. Y el liberalismo, consciente o inconscientemente, sirve los planes del dominio internacional soviético ${ }^{31}$.

En los primeros días de septiembre de 1952, el Departamento de Estado envió un mensaje secreto a la Embajada de Estados Unidos en Colombia, expresando su preocupación "ante la seria posibilidad del retiro del Batallón Colombia", debido a la "renuencia para suministrar armas destinadas a la atención del problema interno". Si el anuncio se efectuaba en la antesala de la próxima Asamblea General de las $\mathrm{Na}$ ciones Unidas, concluía el comunicado, "los efectos serán desfavorables para las naciones del mundo libre". Poco después, Estados Unidos aprobó el envío de un limitado cargamento de armas antipersonales. Colombia no solo no se retiró de Corea, sino que,

30 El Siglo, 22 de julio de 1952.

31 Bernal, José María. (1952). Conferencia. Bogotá: Presidencia de la República, pp. 11 y 15. 
en la Asamblea de Naciones Unidas, presentó una "encomiable intervención" a favor de la política estadounidense 32 .

Los incendios del 6 de septiembre de 1952 distanciaron en definitiva la posibilidad de adquirir armas en Estados Unidos. Ese día, policías de la capital, iracundos tras el sepelio de cinco compañeros ultimados por las guerrillas del Tolima, incendiaron bajo la vista cómplice de las autoridades las instalaciones de El Tiempo y El Espectador, así como las residencias de Alfonso López Pumarejo y Carlos Lleras Restrepo. Ante ello, la opción final del gobierno de Laureano Gómez y Urdaneta consistió en proponer a Estados Unidos el remplazo del Batallón Colombia en Corea por una Batería de artilleros. El Departamento de Estado no entendió las razones: ¿una manera cortés de retirar la infantería? ¿reacción ante las solicitudes de reembolso? Las descartó ambas y aceptó la justificación del embajador colombiano: simplemente el deseo de capacitar, en plena guerra, un cuerpo de artilleros, como lo había hecho con la infantería. La razón auténtica y de fondo que la inteligencia estadounidense no advirtió en este caso pudo ser otra: era la manera más efectiva y honorable de asegurar el retorno inmediato de más de un millar de efectivos con armamento moderno y entrenamiento actualizado en guerra de guerrillas.

El Estado Mayor en Corea no aceptó la propuesta: la sustitución significaba una "ostensible disminución de personal” en el área más necesaria. Corea necesitaba más infantes que artilleros y la diferencia de idioma podría dificultar el apoyo de la artillería colombiana a la infantería aliada. Colombia debería ofrecer una batería complementaria y no excluyente. Pero, aun así, el valor táctico de la nueva unidad no era indispensable. Para el General Rojas, quien propuso personalmente el cambio, lo preocupante fue otro de los argumentos estadounidenses: "la nueva Unidad resultaría en extremo costosa para el gobierno de Colombia”. Rojas se apresuró a oficiar al ministerio de Guerra recomendando que, si los

32 Secret segurity information del Departamento de Estado a la Embajada en Bogotá. Archivo Nacional de Estados Unidos. NND 822905 . gastos en Corea corrían por cuenta de Colombia, "el Comando General considera que las Fuerzas Militares no se hallan en condiciones de continuar indefinidamente con este sacrificio y atender a la vez la actual emergencia de orden público. En consecuencia, este Comando conceptúa que el Batallón Colombia debe retirarse" 33 .

Con Rojas coincidía el comandante del Batallón Colombia, Alberto Ruiz Novoa. En un "mensaje personal y privado", muy diferente de las publicaciones posteriores sobre la participación de Colombia en Corea, Ruiz Novoa informó que las pérdidas del Batallón eran "muy grandes" y se encontraba "reducido a dos compañías de fusileros", a pesar de que "no se ha enviado la rotación que le correspondía salir en estos días y a que se incorporaron 130 reemplazos". En total, para restablecer el Batallón, se necesitarían "400 hombres". En criterio del comandante, llegaba el momento de plantear y decidir si el Batallón continuaba o no en Corea:

Mi apreciación es que la situación se está poniendo "caliente" y que de ahora en adelante las pérdidas serán sostenidas.

Sería cuestión de decidir si el gobierno y el país están obteniendo con la participación del Batallón en Corea las ventajas que necesariamente debemos esperar o no, y en consecuencia resolver si la Unidad continúa aquí o se retira. Si se resuelve retirarla, también sería conveniente resolverlo rápidamente, porque en la actualidad solo tiene dos tercios de su capacidad combativa, lo que constituye una deficiencia para ajustarse a las misiones que le corresponden.

Mi opinión personal es que si no estamos recibiendo un beneficio tangible y con buena voluntad por nuestra participación en Corea, el Batallón debe retirarse. Especialmente por la perspectiva de mayor actividad que significa mayores bajas y por consiguiente mayores gastos en todo sentido, inclusive en prestaciones sociales ${ }^{34}$.

33 APR. Oficio CGFM-C/837, marzo 10 de 1953. Carpeta Número 23 de 1953, folio 229.

34 Mensaje de Alberto Ruiz Novoa al Teniente General Gustavo Rojas. Corea, abril 4 de 1953. APR. Carpeta 23 de 1953. 
La discusión y las negociaciones entre Colombia y Estados Unidos por la dotación de armas y la permanencia de su Batallón en Corea continuaban cuando ocurrió un hecho agradable para Estados Unidos: la caída de Laureano Gómez, aprobada desde el primer momento por el Departamento de Estado. De esta manera no solo se ahorraban la presión por las armas: Laureano Gómez les había incumplido al convocar una Asamblea Nacional que pretendía reformar la Carta con elementos de corte fascista, y podía iniciarse con el general Rojas un replanteamiento sobre la continuación del Batallón Colombia en Corea.

\section{Corea como experiencia}

Entre la segunda administración de López Pumarejo y el gobierno de Laureano Gómez, el Ejército tuvo que asumir dos concepciones prácticas que provocaron en su seno inmensa incertidumbre. Por un lado, el anhelo de cuerpo armado legítimo que pretendía instaurar y fortalecer la profesionalidad de sus efectivos a través de la formación militar y de la preparación para la defensa nacional, se estrelló con una realidad de compromiso en labores de administración pública municipal, departamental y nacional, a la cual se sumó la tarea de juzgar y luego perseguir a los opositores del gobierno. Poco a poco la función de Estado teóricamente atribuible a las Fuerzas Armadas adquirió, en el gobierno de Laureano Gómez, la catadura de partido.

Pero, por otro lado, para responder a las crecientes exigencias del orden público y, en esa labor, de perseguir a la oposición, el Ejército emprendió un difícil tránsito: de fuerza armada formada en las concepciones y en las prácticas de la guerra regular y convencional, aunque con valiosas experiencias en el control del orden público, el Ejército se encontró cada vez más inmiscuido en las concepciones y prácticas de una guerra irregular contra enemigos militarmente organizados en guerrilla. La Justicia Penal Militar aplicada contra los civiles los inmiscuyó también en juzgamientos de carácter político y en guardianes ocasionales de posiciones de partido.

A lo largo de dicho proceso, entre 1946 y 1951, en el seno del Ejército fueron cristalizándose distintas posiciones con respecto a la política en general y al ejercicio del poder en particular. En primer lugar, sectores del alto mando consideraron que la misión del Ejército se encontraba al lado de su Comandante Supremo como representante de un gobierno legítimo. Cualquier pensamiento contrario podría identificarse como deslealtad al Estado o deliberancia indebida y sancionable.

En oposición a veces silenciosa, una franja importante de oficiales subalternos buscó distanciarse de la política. Sentían temor y vergüenza de que los compromisos progresivos con los gobiernos de Ospina y Gómez deterioraran la imagen de las Fuerzas Militares, o de que su compromiso con los conflictos internos terminara alejándolos de su función profesional. La expresión concreta de este sector llegó incluso a concebir la posibilidad de un golpe militar para "salvaguadar la supervivencia de la patria y oponerse a la politización del Ejército”.

Entre ambos sectores lindaba un grupo de oficiales de más difícil ubicación pero que, al observar el proceso seguido por la policía, "rechazaron los intentos conservadores de hacer del Ejército un instrumento de partido". Unos y otros, sin embargo, se limitaron a esperar que los civiles, por sí mismos, resolvieran la aguda y conflictiva situación por la que atravesaba el país. Si bien algunos oficiales se opusieron a la intervención sectaria de las Fuerzas Militares y rechazaron las conductas delictivas que cotidianamente asumían miembros de la policía, la firme respuesta del gobierno cortó cualquier asomo de inquietud.

En estas condiciones, un grueso grupo de oficiales encontró en la preparación que las misiones estadounidenses ofrecían, la brillante estrella que habría de regir sus destinos militares y profesionales. Profundamente influidos a partir del gobierno de Eduardo Santos e inspirados en una nueva teoría occidental que suponía como enemigo principal al comunismo, los oficiales más descontentos con la problemática interna del país se presentaron como voluntarios a Corea.

La guerra constituyó para el Ejército una experiencia modernizante técnicamente, aunque inadecuada para dinamizar el tránsito a las modalidades 
de desarrollo del conflicto de violencia bajo las formas de guerra de guerrillas. De toda Latinoamérica, solo Colombia participó con tropas y unidades navales en el conflicto de Corea, bajo el argumento de "defender la civilización Cristiana"y "evitar que la iniquidad domine la tierra" 35 . La intervención en Corea marcó las tendencias futuras que se presentarían en materia ideológica de los militares. Por Colombia participaron 150 oficiales; de ellos 17 llegaron a comandantes de brigada y uno a ministro de Defensa ${ }^{36}$.

Según el general Valencia Tovar, la experiencia de Corea marcó "huella decisiva en la tecnificación del Ejército y la Armada”, pues, en la circunstancia del conflicto interno que desgarraba al país, se introdujeron "nuevas técnicas de operación sin las cuales se hubiera agravado la inferioridad evidenciada por la Fuerza Pública frente a la Guerrilla en las primeras fases de la confrontación" ${ }^{37}$ :

La lección de Corea, dura y violenta como fue, nos enseñó a combatir, cambiando en breve tiempo todo un esquema de comportamiento militar para hacerlo más profesional y eficiente ${ }^{38}$.

Su aprendizaje, sin embargo, sirvió finalmente a aquello que muchos de los combatientes en Corea examinaban en forma crítica: una vez regresaron, su experiencia se vio comprometida en intensas operaciones de represión, no solo con respecto a la violencia esparcida por los campos $^{39}$, sino incluso contra inermes manifestaciones del conflicto social.

35 El Siglo, 13 de mayo de 1951. Palabras de despedida de Laureano Gómez al Batallón Colombia.

36 Posada, Martín. Ejército y poder burgués en Colombia: El período del Frente Nacional. En revista Uno en Dos 3, Medellín, noviembre de 1976, p. 18.

37 Valencia Tovar, Álvaro. (1976). Sobre la guerra de Corea. en Alternativa 19, Bogotá.

38 Valencia Tovar, Álvaro. Testimonio..., p. 167.

39 Al respecto, véase: Fuerzas Militares de Colombia. Directiva para la organización y entrenamiento del Batallón en el período 21 de enero al 21 de mayo de 1951, Bogotá, spi. El documento contiene una Historia del Batallón Colombia desde la óptica militar, y una síntesis de sus operaciones posteriores: Campaña del Vichada; Operaciones en el Norte del Valle del Cauca; Campaña del Norte del Tolima; Operaciones en el Departamento del Huila e Intendencia del Caquetá; Operación Anorí; Campaña en el Magdalena Medio y Diario de Guerra.
Para entonces, como constató Álvaro Valencia Tovar, "el Ejército Nacional veía diluirse su apoliticidad y con ella su carácter, al paso que la integridad militar cedía lugar al incondicionalismo político"40.

\section{La estrella polar}

Si bien el acercamiento político y militar de Colombia con Estados Unidos se selló ante los peligros de una confrontación mundial y la necesidad de defender el Canal de Panamá a finales de los años treinta; a lo largo de la Segunda Guerra Mundial y, más aún, después de ella, en lo que la historia reconoce como la Guerra Fría, la proximidad de Colombia y de América Latina con la potencia del norte fue mucho más estrecha.

En contra de lo que algunos analistas como Gerhard Drekonja consideran ${ }^{41}$, ni el compromiso de Colombia con Estados Unidos ni su política exterior fueron absolutamente pasivos. Aunque Colombia no participó en la Segunda Guerra al nivel de México o Brasil, quienes enviaron tropas al Pacífico e Italia, respectivamente, es claro que su decisión de apoyar a los aliados en caso de un ataque enemigo sobre Panamá fue más allá de la retórica.

Cierto es que Colombia no necesariamente se ubica a la cabeza de las decisiones en el hemisferio occidental y que, en la mayoría de las ocasiones, su apoyo se basa en las relaciones económicas o en sus aflicciones internas. Pero también es cierto que, a diferencia y algunas veces a despecho de los demás países latinoamericanos, la participación de Colombia en Corea y en Suez refleja su papel definitivo en el respaldo a las políticas estadounidenses.

Aun antes de Olaya Herrera, con el propósito fallido de Rafael Reyes por resolver en forma pragmática el conflicto con respecto a Panamá, o con la doctrina del respice polum formulada por Marco Fidel Suárez, Colombia empezó a observar en Estados Unidos una referencia obligada para todos los aspectos internacionales e incluso nacionales. José Arcadio Buendía, el personaje central de la obra de

40 Valencia Tovar, Álvaro. Testimonio..., p. 188.

41 Drekonja, Gerhard. (1982). Colombia: política exterior. Bogotá: Universidad de los Andes. 
García Márquez, definió con una simbólica frase el derrotero de Colombia: "la única posibilidad de contacto con la civilización es la ruta del norte" 42 . La segunda gran guerra, en la medida en que contrajo la influencia y poder de los europeos en América Latina, consolidó aún más el predominio estadounidense, al punto de convertirlo, prácticamente, en una visión ideológica del papel colombiano en el mundo.

En materia diplomática, cinco hechos definen la consolidación del acercamiento de Colombia a los Estados Unidos al final de la Segunda Guerra e inicios de la Guerra Fría. En primer lugar, la clara política heredada de Eduardo Santos y continuada por la República Liberal, que pone a Colombia en el plano de lo que algunos autores denominan "subordinación activa”43. En segundo lugar, la redacción del Acta de Chapultepec, que pone a Colombia y a su canciller, Alberto Lleras Camargo, como líder continental del sistema panamericano. En tercer lugar, el ingreso de Colombia como miembro fundador de la Organización de Naciones Unidas en 1945, donde brindó importante soporte a las posiciones estadounidenses. No gratuita, ni pasivamente, Colombia hará parte del Consejo de Seguridad, en dos ocasiones, durante los años cincuenta. En cuarto lugar, el Tratado Interamericano de Asistencia Recíproca, del cual Colombia fue un vivo autor e impulsor y que marcó la relación de los ejércitos latinoamericanos con su homólogo del norte. Y, en quinto lugar, el papel fundamental de Colombia en la construcción de la Organización de Estados Americanos, con el significado de adhesión que tal entidad mantuvo.

Aunque pueda argumentarse que la política exterior de Colombia ha correspondido más a los gobiernos que al Estado, es un hecho que, de gobierno en gobierno, las relaciones con Estados Unidos

42 García Márquez, Gabriel. (1967). Cien años de soledad. Bogotá: Editorial Oveja Negra.

43 Torres del Río, César. El presidente Santos y la nueva práctica de la política exterior de Colombia. En Documentos ocasionales. Bogotá: Centro de Estudios Internacionales de la Universidad de los Andes, julio-agosto de 1989. permanecen prácticamente incólumes, se respetan los acuerdos sustanciales y se heredan sus aspectos más trascendentales. Al fin y al cabo, la economía influye en este caso al mundo de la política.

En materia militar, las citas panamericanas que exhortaron a la solidaridad continental en Lima y Panamá (1939), La Habana (1940) y Río de Janeiro (1942), abrieron el marco diplomático para los acuerdos de colaboración militar que empezaron a hacerse efectivos con la Lend-lease Act (Ley de Préstamos y Arriendo, 1941), que permitió la venta de armas y material de guerra a cualquier país cuya defensa se considerara vital para los intereses estadounidenses, y el Inter-American Defense Board (1942), que consintió e indujo el enlace de las Fuerzas Militares en todo el continente. Poco después, en 1947, el Tratado Interamericano de Asistencia Recíproca (TIAR) profundizará y legitimará el predominio militar de Estados Unidos en América Latina.

Sin embargo, para Colombia, luego de los acuerdos concretos y confidenciales durante la República Liberal y de las continuas visitas militares de misiones y alumnos a uno y otro país, el más significativo paso en el acercamiento de Colombia a Estados Unidos fue la tarea que Ospina Pérez depositó en las misiones estadounidenses para que formaran un Batallón de Infantería que sirviera como pilar para la difusión del proceder militar americano en el Ejército colombiano. En adelante, el modelo militar de Estados Unidos se implementó de forma paulatina a través de la obra instructora de las misiones, la reorganización y modificación del sistema de Estado Mayor que el Ejército heredaba aún de las misiones chilenas, o incluso el cambio de uniforme.

Como en la preguerra lo hizo el presidente liberal Eduardo Santos, en diciembre de 1951, bajo los fragores de la Guerra Fría, Colombia rubricó un acuerdo informal y secreto que dejaba en manos de Estados Unidos la coordinación de las operaciones dentro de las rutas marítimas y aéreas para la protección del Canal de Panamá y el Mar Caribe en caso de agresión soviética, y reafirmó que cada país pondría a disposición mutua los recursos militares, navales y 
aéreos indispensables para las operaciones militares "en defensa del hemisferio" 44 . Este fue, precisamente, un acuerdo que el gobierno conservador de Gómez intentó utilizar para las adquisiciones de armas y tecnología dedicadas al control interno.

Meses después, en 1952, un acuerdo suscrito por el canciller colombiano Gonzalo Restrepo y el embajador estadounidense Capus M. Wainick, consolidó sobre la política de ambos Estados las decisiones en materia militar. Compuesto por once artículos, el acuerdo estableció el suministro de equipos, materiales y ayuda militar para "la defensa y la paz del hemisferio occidental", la permanencia indefinida de las misiones militares con carácter de personal diplomático y con las garantías correspondientes, el control del comercio con las naciones que amenazaran la seguridad continental, e incremento, por parte de Colombia, de su propia fuerza defensiva ${ }^{45}$.

Sobre el terreno, la influencia militar de Estados Unidos en Colombia se puso de presente con las enseñanzas que sobre la Guerra de Corea aplicaron los

\section{Bibliografía}

Atehortúa, Adolfo. (1994). Estado y Fuerzas Armadas en Colombia. Bogotá: Tercer Mundo: Pontificia Universidad Javeriana, Cali.

Bernal, José María. (1951). Memoria del Ministerio de Guerra 1950-1951. Bogotá: Imprenta del Comando General de las Fuerzas Militares.

Bernal, José María. (1952). Conferencia. Bogotá: Presidencia de la República.

Bermúdez, Gonzalo. (1982). El poder militar en Colombia. De la Colonia al Frente Nacional. Bogotá: Editorial América Latina.

Blair, Elsa. (1993). Las Fuerzas Armadas. Una mirada civil. Bogotá: Cinep.

Bushnell, David. (1984). Eduardo Santos y la Política del Buen Vecino. Bogotá: El Áncora Editores.

44 El texto original del acuerdo reposa en el Archivo de la Presidencia de la República bajo el título SECRETO. Plan de los gobiernos de Colombia y de los Estados Unidos de Norteamérica para su defensa común. Embajada de Colombia, Washington, 31 de diciembre de 1951. APR, 1954, Caja 843.

45 El Tiempo, 18 de abril de 1952. oficiales para la confrontación de las guerrillas en el país. Las reformas orgánicas en la disposición interna de las Fuerzas Armadas, la Escuela de Lanceros, el Batallón de Policía Militar y el Batallón Antiaéreo de Armas Automáticas, constituyen una muestra sobre la acogida del modelo estadounidense ${ }^{46}$. De hecho, la misma Guerra de Corea y los constantes intercambios entre una y otra fuerza lograron cimentar en los oficiales y soldados colombianos un "espíritu de cuerpo" que no habían sentido antes con respecto a sus similares del norte. El armamento y la tecnología militar procedente de Estados Unidos se convirtieron, además, en una importante vía de relación y dependencia de las Fuerzas Militares colombianas. A ello se sumó la dependencia en órdenes distintos, entre ellos, desde luego, la ideológica. En las publicaciones de las Fuerzas Armadas colombianas desaparecieron paulatinamente las referencias y simpatías con respecto a los ejércitos de Europa y apareció la relación permanente al modelo estadounidense. 凤

Dávila, Andrés. (1998). El juego del poder. Bogotá: CerecUniandes.

Drekonja, Gerhard. (1982). Colombia: Política Exterior. Bogotá: Universidad de los Andes.

Escuela de Lanceros. Reseña histórica sobre las unidades rangers. Revista Militar, III (9), septiembre de 1957.

Fluharty, Vernon. (1981). La danza de los millones. Régimen militar y revolución social. Bogotá: El Áncora, Editores.

Franco I., Eduardo. (1976). Las guerrillas del Llano. Medellín: Editorial Hombre Nuevo.

Galvis, S. y Donadio, A. (1988). El Jefe Supremo. Bogotá: Planeta.

Galvis, S. y Donadio, A. (1986). Colombia Nazi. Bogotá: Planeta.

46 Obsérvese, al respecto, Rodríguez, Saúl Mauricio. (2006). La influencia de los Estados Unidos en el Ejército colombiano, 1951-1959. Medellín: La Carreta - Universidad Nacional de Colombia. 
Guzmán, C., Germán y otros. (1986). La Violencia en

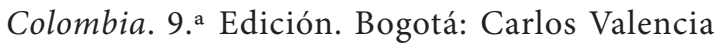
Editores.

Icenhour, James. (1976). The military in Colombia Politics. Dissertation Ph.D., The George Washington University.

Leal, Francisco. (1984). Estado y política en Colombia. Bogotá: Siglo XXI Editores. Cerec.

Leal, Francisco. (1994). El oficio de la guerra. Bogotá: Tercer Mundo-Iepri.

Leal, Francisco. (2002). La seguridad nacional a la deriva. Del Frente Nacional a la posguerra fría. Bogotá:Alfaomega - Ceso-Uniandes - Flacso, Sede Ecuador,

Maingot, Anthony. 1967. Colombia: civil-military relations in a Political culture of conflict, Dissertation Ph.D., University of Florida.

Maulin, Richard. (1973). Soldiers, guerrillas and politics in Colombia. Lexington: Lexington Books.

Medina, Hernando. Si yo fuera el Comandante del Ejército. Bogotá, 12 de diciembre de 1956. APR, Secretaría General, Fuerzas Militares, caja 2, carpeta 71 , folio 287.

Mury, Willy. (1975). L'armée colombienne. Etude d'une institution militaire dans ses rapports avec la société en transition, 1930-1974. Tesis de doctorado, Universidad de París.

Oquist, Paul. (1978). Violencia, conflicto y política en Colombia. Bogotá: IEC.

Ortiz, Carlos M. (1978). Estado y subversión en Colombia. La violencia en el Quindío. Años 50. Bogotá: CiderCerec.

París, Gabriel. Declaraciones concedidas a El Tiempo, Lecturas Dominicales, octubre de 1996.

Pécaut, Daniel. (1987). Orden y violencia. 1930-1954. Bogotá: Siglo XXI Editores,

Pécaut, Daniel. (2003). Violencia y política en Colombia. Elementos de reflexión. Medellín: Hombre Nuevo Editores - Universidad del Valle.

Pinzón, Patricia. (1994). El ejército y las elecciones. Bogotá: Cerec.

Pizarro, Eduardo. La profesionalización militar en Colombia, Análisis Político 1, 2 y 3,(1987-1988). Bogotá: Iepri-Universidad Nacional de Colombia.

Puyana, Gabriel. (1993). ¡ Por la libertad en tierra extraña! Bogotá: Banco de la República.
Puyana, Gabriel. (2001). Vivencias de un ideal. Relatos que pueden ser historia. Bogotá: Editora Guadalupe.

Ramsey, Russell. (1981). Guerrilleros y soldados. Bogotá, Tercer Mundo.

Rodríguez, José Jaime. El Ejército del siglo XX. De Reyes a López. La reforma militar. En: Historia de las Fuerzas Militares de Colombia. Ejército. Vol. II, capítulo 28 Bogotá: Planeta, 1993.

Rodríguez, Saúl Mauricio. (2006). La influencia de los Estados Unidos en el Ejército colombiano, 1951-1959. Medellín: La Carreta - Universidad Nacional de Colombia.

Rojas Pinilla, Gustavo. (1954). Bienvenida a la Patria. Saludo del General Rojas al regreso del Batallón Colombia, 30 de noviembre de 1954. En Mensajes y discursos. Bogotá: Imprenta Nacional de Colombia.

Rojas Pinilla, Gustavo. Las guerrillas en el Llano y otras cosas más. Revista de Historia, 1 (1), agosto de 1975. Bogotá: Banco de la República-Uniandes, 1993.

Rojas, María Eugenia. (2000). Rojas Pinilla, mi padre. Bogotá: Panamericana.

Rueda Vargas, Tomás. (1944).El Ejército Nacional. Bogotá: Librería Colombiana, Camacho Roldán y Cia. Ltda., Editorial Antena.

Ruiz Novoa, Alberto. (1956). El Batallón Colombia en Corea. Bogotá: Empresa Nacional de Publicaciones.

Ruiz Novoa, Alberto. (1965). El gran desafío. Bogotá: Tercer Mundo.

Ruiz Novoa, Alberto. (1956). Enseñanzas militares de la campaña de Corea aplicables al Ejército de Colombia. Bogotá: Antares.

Sáenz, Eduardo. (2002). Colombia años 50. Industriales, política y diplomacia. Bogotá: Universidad Nacional de Colombia.

Sánchez, Gonzalo y Peñaranda, Ricardo. (1986). Pasado y Presente de la Violencia en Colombia. Bogotá: Cerec.

Serpa, Jorge. (1999). Rojas Pinilla. Una historia del siglo XX. Bogotá: Planeta.

Studer W., Robert. (1975). The Colombian Army: Political aspects of its role. Dissertation Ph.D., University of Southern California.

Téllez, Édgar y Sánchez, Álvaro. (2003). Ruidos de sables. Bogotá: Planeta.

Torres A., Pablo. (1958). Colombia en la Guerra de Corea. Impresiones de un combatiente. Bogotá, spi. 
Torres del Río, César. (2000). Fuerzas Armadas y seguridad nacional. Bogotá: Planeta.

Valencia Tovar, Álvaro. (1992). Testimonio de una Epoca. Bogotá: Planeta.

Valencia Tovar, Álvaro. (1976). Sobre la guerra de Corea, Alternativa 19 Bogotá.

Valencia Tovar, Álvaro (comp.). (1996). Historia de las Fuerzas Armadas en Colombia. Bogotá: Planeta.

Valencia Tovar, Álvaro. Historia militar contemporánea. En Nueva Historia de Colombia (NHC).

Valencia Tovar, Álvaro y Sandoval, Jairo. (2001). Colombia en la guerra de Corea. La historia secreta. Bogotá: Planeta.

Varela, David Fernando. (1998). Documentos de la Embajada. Bogotá: Planeta.

Vargas, Alejo. (2002). Las Fuerzas Armadas en el conflicto colombiano. Bogotá: Intermedio.
Vernon Lee, Fluharty. (1981). La danza de los millones. Bogotá: El Áncora Editores.

\section{Archivos consultados}

Archivo General de la Nación. Bogotá, Colombia. AGN. Archivo de la Presidencia de la República. Bogotá, Colombia. APR.

Archivo General del Ministerio de Defensa. Bogotá, Colombia. ANAC.

The National Archives. Washington y Maryland, USA. NA.

The National Security Archive. Washington, USA. NSA.

\section{Prensa}

El Espectador. Bogotá, 1948-1958.

El Siglo. Bogotá, 1948-1958.

El Tiempo. Bogotá, 1948-1958. 